\title{
Deciphering the Libor and Euribor Spreads During the Subprime Crisis
}

\author{
L. Pelizzon and D. Sartore ${ }^{+}$
}

January 2013

\begin{abstract}
:
This paper investigates the key role played by different factors, such as the use of Asset Backed Commercial Paper as collaterals in the short-term debt market, credit risk and the injection of liquidity by Central Banks through so-called unconventional measures, on the persistent spread during the subprime crisis bet. The empirical analysis shows that, in addition to credit risk, a relevant variable for explaining the interbank rate dynamics is the outstanding volume in the Asset Backed Commercial Paper market. In short, the large spread observed in the market is explained by the inter-relationship between collateralized short-term debt markets and the unsecured interbank market. It is also shown that Central Bank "non-conventional" intervention variables are relevant in affecting the spread both in the long-run but mostly in the short-run.
\end{abstract}

Keywords: Subprime Crisis, Collateral, Liquidity, Unconventional Monetary Policy.

\footnotetext{
${ }^{+}$All the authors are at the University Ca' Foscari of Venice. Contact authors: Loriana Pelizzon, Dpt. of Economics, Cannaregio 873, 30121 Venice, Italy. Tel.: +39 0412349164 Fax: +39 0412349176 e-mail: Loriana.Pelizzon@unive.it

We thank the referee for helpful comments and discussion and Roberto Vendramin and Federica Zabotto for excellent research assistance.
} 


\section{Introduction}

Since August 2007 we are experiencing in the international financial market what many call the worst financial crisis since the Great Depression of the 20s. Housing prices are falling after a decade of sky-rock flight in a worrying bubble-bust fashion, banks are experiencing huge losses due to "ponzi" investments betting on the never-ending house market inflation, financial innovations spread the losses to the entire bank system so that even a medium-size financial institution are likely to be seen as too-big-to-fail.

Many authors try to give a systemic view of the Subprime phenomenon and the consequent financial and economic crisis (Gorton, 2008 and Brunnermeier,2008 are two good examples), trying to deciphering all the main variables which probably took us at this point (housing bubble, securitisation, leverage and shortening of the debt maturity structure, rating agency models,...). With this paper we focus the more on a particular feature of the crisis: the tension in the money market and specifically the interrelationship between collateralized short term debt markets and the unsecured interbank market.

In fact, one of the most puzzling phenomena we are facing during the current crisis is the unusually volatile dynamic that affects the money market unsecured interest rates (benchmarked by the Libor and the Euribor rates) in the main financial markets. In normal times, the interbank market rates are strictly connected to the expected policy rate fixed by the Central Banks and usually lie above these rates by a constant amount of basis points (the risk premium).

The strict link between the interbank rate and the policy rate is fundamental for the efficiency of the monetary policy, indeed the 3 (or 6) months interbank market rates are the benchmark rates on which the financial institutions calculate the mortgage and loan rates for household and firms. If these rates are strictly connected in a constant fashion to the key policy rates, a change in the later will be fully transferred to the former and through these to the credit rates on mortgages and loans and more generally to the real economy. However, if this condition does not hold and the spread between the interbank rates and the expected key policy rates (later on the "Spread") is not constant but is a function of some market variables that conventional instruments of the Central Banks cannot influence, the monetary policy effectiveness is mined. This is unfortunately exactly what happens during the current crisis.

Thus it becomes extremely important to understand: (i) which variables are actually affecting the spread during this period, and (ii) weather the new actions Central Banks implemented have produced some results.

In this paper we investigate the two above issues and in particular we concentrate on the interrelation between the collateralized money markets and the unsecured money market: the interbank market. The main reason in fact for the interbank market rate to raise largely above the monetary policy rates is the tension between demand and supply of liquidity of short-term funding. If the supply falls short of the demand the price will tend to go up, above the Central Bank rate. Under normal condition, if there are these liquidity tensions the Central Bank injects liquidity in the money market through its Open Market Operations (OMOs), rising the supply of money and steering the money market rate back down to the key monetary policy rate. However, since during the current crisis the Central Banks were quite ineffective in doing so, we should investigate what kind of liquidity tensions the market experienced and why the injection of central money was unable to calm down this tension. 
The answer to this question can be found investigating (i) the structural framework of the money market, (ii) the reasons behind financial institutions demand in the different segments of the money market during the last $4-5$ years and (iii) the tools the Central Banks hold to act in the money market.

Another important aspect that needs to be considered is that the Spread is not affected only by the liquidity tensions but also by the credit risk as highlighted by Taylor and Williams (2009). Indeed the 3 months bank loans benchmarked by the Euribor/Libor rates have a higher credit risk attached then an overnight loans benchmarked by the Eonia/Overnight Libor. Credit risk that arises from the probability that the bank in 3 months defaults and therefore would be not able to pay back the loan.

The last issue we investigate in this paper is whether the Central Banks and Government intervention policies were able to affect the Spread.

In the paper we present some indicator of these notional variable of liquidity tension, credit risk and policy intervention and we investigate which one of them are empirically able to explain the Spread dynamic during the current crisis.

From the theoretical point of view our reading of the crisis feet into the well-known analytical framework of Diamond and Dybvig (1983, 2000) bank run model, the Fisherian debt-deflation model and the Bernanke and Gertler (1995, 1996) and Holmstrom and Tirol (1997) financial accelerator model. Moreover, our investigation of the crisis is also in line with Brunnermeier (2009) and Adrian and Shin (2010,2011).

On one hand this paper follows the main literature on the topic (Taylor and Williams 2009, McAndrews, Asani and Wang 2008, Michaud and Upper 2008, Wu 2008 among others) that tries to disentangle the liquidity and the credit risk effect on the spread and investigate if the policy intervention can be effective in take it down. On the other hand it uses different indicators for the liquidity and credit risk in line with the Diamond and Dybvig $(1983,2000)$ bank run model theoretical framework.

The paper is organized as follows. In the next section we present the theoretical framework behind the liquidity tension. In section 2 we discuss major money market events during the Subprime crisis period, in section 3 we present the data modelling approach and the results. In section 4 we conclude.

\section{Money market dynamic and liquidity tension during the Subprime crisis.}

The unsecured money market, both for the USDollar and the Euro, is a really important segment for the overall economy because the 3 and 6 months Euribor and Libor are the benchmark rates used by the financial sector to calculate the household and firms' loans rate. But although the great importance given to these rates the term segment of the unsecured money market is a really thin market.

The actual amount of the overall outstanding contract in the unsecured market is not available; therefore, it is almost impossible to know exactly the total amount of the term unsecured segment either. The 2007 ECB money market study reports that more than $90 \%$ of the overall transaction have a "less than 1 week" maturity and probably also the other $10 \%$ is concentrated to "less than one month" maturities. ${ }^{1}$

From this evidence we can argue that longer-term part of the market (i.e. say "more than 1 month" maturities) should be really thin and have the role of clearing the residual

\footnotetext{
${ }^{1}$ These results even strengthened during the crisis period.
} 
amount of liquidity demand that arises in other segments of the money market and of the financial sector rather than the role of financing the bulk of the financial system liquidity demand.

On the other hand the short-term securities market, represented by the Commercial Papers (CPs) and the Asset Backed Commercial Papers (ABCPs), has a longer maturity distribution and a completely different role.

The average maturity of the CDs, the CPs and the ABCPs is 30 days and there is quite a good presence of securities with longer maturities as well. Therefore, the bulk of the term liquidity is raised in this market. The reason of this is that the unsecured market is mainly a market between banks, while the market of securities is a market where investors have a prominent participation.

Under this framework we have that if a segment of the short-term securities market will freeze up, then the unsecured interbank market alone cannot tune all the short term liquidity demand. Indeed the shock creates a higher liquidity demand of the entire bank system and it cannot be supplied by the agents inside the system itself. There must be an infusion of liquidity through other money market segments (i.e. the Central Banks Open Market Operations or rising volumes in other securities issued). If this does not happen, the un-supplied liquidity demand of the agents holds and the price of the unsecured interbank loans must rise.

Thus, a good indicator for the liquidity tensions in the interbank money market is the dynamic in the short-term securities markets.

Searching for a market variables reflecting the first aspect, a perfect one is the outstanding volumes of papers issued by banks in the short-term securities market, in particular CDs, the CPs and the ABCPs. Many can argue that we are watching the picture upside down because actually the Euribor/Libor rates are those which influence the CDs, CPs and ABCPs' outstanding volumes, via the influence they have on the CDs, CPs and ABCPs' rates. However, if under normal conditions this is absolutely true, when there is a shock in one of those securities market the relationship is inverted because the crisis creates a systemic need of liquidity in the banking system.

A shock in the the short-term securities market is amplified by two main features that characterized the modern investment banking system: the use of leverage debt and the shortening of the maturity structure in the capital market. The first phenomenon was over-pushed in the later years.

Under these conditions usually the financial system can perform really well if everything goes in the right way, but there is an elevate risk that, if something goes wrong, the possible losses can be enormous and the financial crisis can be inevitable.

The shortening of the debt maturity structure was a really common phenomenon as well. Over the years the financial sector tended to finance an increasing part of its assets with short-term borrowing in the money market.

In particular, banks prefer to finance the long term assets, rolling over short term loans in the money market rather than using long term contracts in the capital market. With this technique, on one hand, they have both a lower cost of debt (usually short-term debt is cheaper) and more "windows" in which they can resell the assets (gaining from secondary market movements) but, on the other hand, they face an increased liquidity risk, since they are not sure they can roll over the short-term refinancing every time.

In line with the traditional Diamond and Dybvig (1983) bank run model, banks have created a large liquidity mismatch between assets and liabilities that exposes them to a bank run. During the Subprime crisis, the run won't be caused by the depositors (like in 
the commercial bank model) but it is caused by the lenders in the money market. If they believe that the solvability of the bank is compromised, they won't roll over the shortterm loan pushing the banks in a crisis of liquidity.

The financial system can raise leverage debt in the money market in three main ways: (i) secured transactions, (ii) unsecured transactions and (iii) securitisation.

The first way is the safer and the cheapest one, but it entails that the bank uses high quality assets as collateral on the loan. The bigger part of the money market secured transactions are General Collateral (GC) repos ${ }^{2}$. Also other high rating assets can be used in secured transaction but, to our knowledge, there is no information on the kind of assets usually exchanged.

Also the Central banks' OMOs are secured transaction that can be used to increase leverage debt. However the collaterals eligible for these repos are wider then in the former case. The FED before the 2007 crisis accepts only Treasury Bonds, the ECB accepts all marketable debt instruments in addiction to Treasury Bonds, like Covered and not Covered Bank Bonds, Corporate Bonds and ABS with the only restriction (before the crisis) that they must have a low default risk (i.e. at least Rating A).

Another way to increase the leverage on the money market is using the securitisation process based on $\mathrm{ABCP}$ programs. $\mathrm{ABCPs}$ are a sort of collateralised $\mathrm{CP}$, where the $\mathrm{CP}$ is backed by the cash flow deriving by different kinds of receivables (such as mortgage and consumer debt receivables, auto and equipment loans and leases) or others ABSs (such as CDOs, squared CDOs, MBSs, etc.).

The second way through which the financial system can increase its leverage in the money market is the unsecured transactions. In this case the bank borrows unsecured and invest this liquidity in any kind of asset. Unsecured landing capacity does not depend on the collateral quality, but is strictly correlated to the bank's ability to be solvent.

The process behind the rise in leverage positions using secured debt is almost the same in all markets ( $\mathrm{GC}$ repo, ECB's $\mathrm{OMO}$ and $\mathrm{ABCP}$ ) and it consists in buying assets and then using them as collateral to obtain more money to buy other assets.

Finally, although in the unsecured market the bank does not have to use collateral, also in this market the process is the same: the bank will go and ask liquidity to buy assets and each time it has to roll over the position in order to maintain its leverage.

The different kind of assets tends to be financed in different segments of the money market. If a bank has to maintain a leverage on Treasury it uses the GC repo market and the ECB's OMOs (it is cheaper than other money market segments), if it has to maintain the leverage in the ABS market it borrows in the ABCP market and finally, if it has to maintain the leverage in junk risky assets (rating lower than $\mathrm{A}$ ) it uses and roll over positions in the unsecured market.

The more a financial system is leveraged, the more the Central banks are ineffective to provide the liquidity needed in presence of a liquidity crisis.

This effect comes from two pathologies (which affected the financial system during the last years): (i) the assets price deflation and (ii) the bank run in the money market. If those conditions hold together in presence of high leverage there is a high probability that the Central Banks are unable to give to the system the right amount of liquidity it needs with their ordinary tools (liquidity against collateral) because banks are not holding the high quality collateral needed to borrow from the Central Bank.

\footnotetext{
${ }^{2}$ A GC repo which are agreement between two parties whereby one party sells the other a Treasury Bond at a specified price with a commitment to buy the security back at a later date for another specified price
} 
If there is an asset deflation in all the segments, and the Central Bank could not provide the necessary support, one possible solution is to find additional liquidity in the unsecured segment of the money market. In this market collaterals are not binding and the bank can raise the liquidity it needs.

This means that the financial system possible asset deflation can be rolled over in the money market only with the unsecured segment (Euribor-Libor markets), while neither the GC repo market nor the ECB's OMOs can have this purpose.

All the trouble in the money market and in the financial system started to materialise when the ABCP market froze up.

In a ABCP program, as other securitisation transaction, a sponsor bank creates a Special Investment Vehicle (SIV) which has the purpose to purchase receivables, CDOs and other ABS from the sponsor bank and rise liquidity in the capital market using the cash flow deriving from these ABS.

Under these conditions, when during the first part of the 2007, the US Subprime mortgage market deteriorated, the investors became the more in more worried by the solvability of many $\mathrm{ABCP}$ program backed by those mortgages and by CDOs built on those mortgages.

All the ABCP programs not fully supported started to be run by investors, worried about the possibility of losing a part or all their money.

The banks, after taking on their balance sheet the program's assets, must now roll the ABS used as collateral in the run ABCP programs in other market (short-term or long term) and they also have to find out the liquidity needed to cover the difference between the market value of the not-run ABCP programs and the market value of the ABS used as collateral. From a systemic point of view the total amount of liquidity needed by a high leveraged financial system is equal to the decreased amount of outstanding volume of the ABCP programs. This liquidity can also be viewed as the rise in liquidity demand in other money market segments.

Only the A-rating ABS can be rolled at the Central Banks ${ }^{3}$ and just the depositary institution can participate at the OMOs.

A large part of this liquidity demand had to be covered in the unsecured money market (Euribor/Libor segments). Moreover, since the ABCP programs subject to run were those with riskier assets in their balance sheet, the big part of the collateral that are no more financed are those not eligible at the central banks' OMO but which has to be financed with unsecured debt. The huge demand of liquidity at the aggregate level pushed higher the interbank rates.

\section{A Model for the interbank rate}

The money market rates can be decomposed into several factors that reflect the characteristics of the borrowing banks as well as market wise conditions. As a consequence, the consensus in the literature is that the interbank rate can be affected by the following variables: (i) Expectations on the monetary policy in the next three months, (ii) Credit risk attached to the unsecured landing, (iii) Liquidity tension present in the market and (iv) Central Banks ad hoc interventions. The liquidity risk is

\footnotetext{
${ }^{3}$ Note that at the very beginning of the crisis the FED and the BOE did not have this facility, but they had to introduce it as long as they wanted to sustain at list a part of this liquidity demand.
} 
represented by the funding liquidity needs of the borrowing. The credit or counterparty risk is the compensation for the risk of default of the borrowing bank.

The model is represented as:

$$
I R_{t}=f\left(\operatorname{Exp}\left(R_{f, t}\right) ; C_{t} ; L_{t} ; C B I_{t}\right)
$$

where $I R$ is the Interbank rate, $\operatorname{Exp}\left(R_{f, t}\right)$ is the expectation at time $\mathrm{t}$ of the monetary policy reference rate after $n$ months., $C B I$ is the group of several indicators of policy interventions, $C$ is our variable of credit risk and $L$ the one for the liquidity tensions.

To take out the pure expectation effects on the 3 months Euribor rate we need a market variable which can reflect the market expectation about future monetary policy. A good candidate is the three months Overnight Indexed Swap (OIS), also called Eonia swap for the European money market. This rate is closely connected to the average overnight interest rate expected to prevail over the next three months, since is the rate at which banks swap overnight rate (Eonia) at three months maturity.

Under these conditions, we can clear the expectation effects on the 3 months Euribor using the three months OIS.

The 3 months Libor-OIS or Euribor-OIS spreads will thus reflect the components of the unsecured rate which is affected just by liquidity risk, credit risk and Central Banks Interventions. That is:

$$
\text { Spread }_{t}=f\left(C_{t} ; L_{t} ; C B I_{t}\right)
$$

Thus, we have to focus on the role of the three left variables had taken to this phenomenon.

\subsection{Liquidity risk indicators $\left(L_{t}\right)$}

Our analysis suggests that indicators for the liquidity tension phenomenon described above are the market liquidity conditions in the different segments of the money markets. Data on market liquidity conditions are not easily available. The only data that fit to our purposes are CPs and ABCPs' outstanding volumes, for three main reasons. First, because the main source of the current turmoil in the money market is the ABCP market. Second, if the liquidity demand is due to a run and asset deflation in the low rating securitised segment (ABCP for example) the losses must be adsorbed in the unsecured segment (the Euribor/Libor market and CPs markets). Third, the outstanding volumes can reflect both the bank run phenomenon and the asset deflation phenomenon (if the lenders does not run, the short term debt volume decreases just in the amount of the collateral assets deflation, if the lenders run the volume decreases of all the amount of the loan).

In line with Bruneirmeier and Pedersen (2008), a second indicator for funding and market liquidity is the volatility. The intuition is that since liquidity risk tends to increase price volatility, and since an uninformed financier may interpret price volatility as fundamental volatility, this increases margins and margin calls. Indeed if there are more volatility in the market prices also the margin calls on feature and derivative contracts will be pushed up, putting additional pressure on the financial institutions' 
liquidity demand. Therefore, a second indicator for liquidity risk is VIX: the Chicago Board Options Exchange Volatility Index.

\subsection{Credit risk indicators $\left(C_{t}\right)$}

The Euribor/Libor transactions are unsecured transactions between banks. Therefore, the price of those transactions has to entails a credit risk premium. The higher is the risk of a banks' default the larger is the price on unsecured loans. A commonly used indicator for the financial institutions' credit risk is the Credit Default Swap index for the financial sector. In our analysis we use the CDS Index for the United States for both the Euribor and the Libor markets.

A second variable that is also related to credit risk is volatility. In fact, an increase in the volatility in the equity market increases the probability of defaults and reduces the bond prices and therefore increases the bond yield and the credit spread.

The VIX, can thus became another measure of the credit risk that can affect the Spread in the short-term.

\subsection{Indicators for Central Banks interventions $\left(C B I_{t}\right)$}

We consider the indicators for Central Banks interventions by summarizing the analysis done in Casarin, Sartore and Zabotto (2012), where some suggestions to reconstruct measures of the ECB and the FED liquidity injection variables are given.

\subsubsection{The ECB's intervention policy}

ECB reacts to the financial crisis with two categories of measures: actions toward the interventions on the interest rate, called "standard measures" and the "enhanced credit support", called "non standard".

In a condition of liquidity scarcity, the refinancing (REFI) rate is a good instrument to act in the interbank rate because of their sensitivity to the REFI fluctuations

Inside the "enhanced credit support" special program we focus on ECB refinancing operations with different maturities. We consider two types of refinancing operation: LTROs and MROs; both of them are open market operations (OMOs) but with a different duration. LTROs and MROs stand for long-term liquidity and short-term liquidity respectively. Before the crisis there were only two ways of refinancing operations: MROs with a one-week maturity and LTROs with a three-month maturity. During the crisis, ECB modified the refinancing operations features increasing the frequency of LTROs and introducing new LTROs with one-month, six-month and twelve-month maturities. The ECB provided huge amounts of liquidity to the banking system through both regular and special OMOs; first of all, it increased the allotted amount to meet liquidity needs via MROs and LTROs. In front of the strong demand for liquidity, ECB used fixed-rate tenders with full allotment with the aim of satisfying bank's liquidity need in its entirety. Furthermore, the Central Bank introduced very long LTROs with one-year maturity. 
All the amounts both in LTROs and in MROs are distributed through working days among tenders and through the maturity of the operation ${ }^{4}$.

For both LTROs and MROs analysis we consider the variables:

- Bid amount; represents the liquidity need of the ECB's counterparts; it is the amount that the counterparts offer as a guarantee of the allotment received through LTROs.

- Number of bidders; is the number of subjects that benefit from the use of liquidity issued by the ECB at a certain instant.

- Allotted amount; is the quantity of money in circulation due to the ECB monetary policy.

- Satisfaction rate; gives information about the percentage of satisfaction given by the ECB to the counterparts bids.

\subsubsection{The Federal Reserve intervention policies}

Likewise to the European Central Bank, FED as well reacted to the crisis going beyond the cutting of the federal funds target rate. It implemented a number of programs with the aim of supporting the financial institutions liquidity and improving the conditions in the financial markets.

Regarding the FED reference rate, it is well known that the Federal Open Market Committee (FOMC) adjusts the rate in its regular meetings but it can also be adjusted in emergency meetings. The Federal Funds Target Rate passed from 5-1/4 percent in 2006 to actually zero at the end of 2008 .

Other peculiar actions implemented by FED during the financial turmoil can be divided in three groups.

The first group of programs consists of a short-term liquidity supply addressed to banks, depository institutions and financial institutions. This group includes:

- the traditional discount window;

- TAF, Term Auction Facility; established in December 2007 to meet the demands for term funding more directly than the discount window, considered by many banks as a signal of financial weakness.

- PDCF, Primary Dealer Credit Facility; established in March 2008 in response to the tensions in the tripartite repurchase agreement market. The PDCF consists of an overnight loan facility for primary dealers and it functions similarly to the FED discount window for depository institutions.

- TSLF, Term Securities Lending Facility; established by the FED in March 2008 to approach the pressure faced by primary dealers in their access to term funding and collaterals. Under this program, the FED loaned liquid Treasury securities to primary dealers with a fee for one month in exchange for eligible collateral, including also less liquid securities. Loans were allocated through auctions.

\footnotetext{
${ }^{4}$ Details for the computations of the indicators are reported on Casarin, Sartore and Zabotto (2012).
} 
The second group of actions implies the supply of liquidity directly to borrowers and investors in the credit market. This category consists of:

- CPFF, Commercial Paper Funding Facility; established by the FED in October 2008 in order to address the strains in the commercial paper market. With this facility, FED provided liquidity to US issuers of commercial paper when that credit was not available in the market.

- AMLF, Asset-Backed Commercial Paper Money Market Mutual Fund Liquidity Facility; introduced in September 2008 to help Money Market Mutual Funds (MMMFs), that held ABCP to meet investors' demands for redemptions and to support liquidity in the ABCP market and, more generally, in the money market.

- MMIFF, Money Market Investor Funding Facility; a supplement to the AMLF introduced in October 2008 and it had the similar purpose of increasing the liquidity available to MMMFs.

- TALF, Term Asset-Backed Securities Loan Facility; introduced by FED in November 2008, in cooperation with the U.S. Department of Treasury, with the purpose of stimulating the issue of securities backed by privately originated loans to consumers and business and of improving market conditions for ABS.

A third group of instruments includes:

- Purchase of long-term securities for the Federal Reserve portfolio in order to support the functioning of credit market.

All these programs were established by the FED under the Authority of the Federal Reserve Act in order to provide liquidity directly to borrowers and investors in the credit market; some of the programs ran for a short-medium period and stopped when the conditions in the financial markets have improved ${ }^{5}$.

Data are available with different information not only compared with the ECB data but also with the FED facilities. To compare the two CBs liquidity injections, for FED data we consider the same variables used in ECB case: Bid amount, Number of bidders, Allotted amount and Satisfaction rate.

In our regression analysis we avoid to use the Bid amounts and the Numbers of bidders as variables because they are collinear or quasi-collinear to the allotted amounts.

\section{Modelling the 3 months Euribor (Libor) Spread}

\subsection{Variables and descriptive statistics}

The sample period considered is from January 18, 2006 to January 12, 2011. Consequently, for each observable or computed variable we have 261 weekly data that correspond exactly to 5 years. In January 2011 we can consider ended the Subprime crisis, even though the financial crisis has continued as Sovereign crisis.

Figure 3.1.1 plots the spread between the 3 month Euribor and the Eonia swap and the spread between the Libor and the OIS in dollar. The picture seems quite the same for both currencies and similar pattern can be found also in the spread in sterling pounds and yen.

\footnotetext{
${ }^{5}$ On $30^{\text {th }}$ October 2009, MMIFF expired; subsequently, on $1^{\text {st }}$ February 2010, AMLF, CPFF, PDCF and TSLF were closed while the final TAF was affected on $8^{\text {th }}$ March 2010.
} 
Before the crisis there was a constant spread between the expected central bank rate and the unsecured money market rate. With the crisis this spread widens up and became quite volatile. Sample data show the crisis jump at the second week of August 2007.

In the analysis we presented above we identify three main groups of variables that can affect the spread dynamic: the liquidity risk variables, the credit risk variables and the Central Bank intervention variables.

In the previous section 2.3 we have done a wide description of the CBI (Central Banks Intervention) variables. Here we give some brief description of the liquidity and credit risk variables that is of the volume on the Commercial Paper markets, VIX, CDS.

The volume of the Commercial Papers market is characterized in our analysis by the ABCP outstanding volumes and the volumes of Commercial Paper issued by financial institutions $(F C P)$. Data are from the weekly FED release. As the results shows later, they incorporate enough information to well explain the liquidity tensions dynamic ${ }^{6}$.

[Insert Figure 3.1.2]

The other variables we use are the VIX and the Credit Default Swap Index for the US financial sector $(C D S)$. The weekly series of these variables are calculated using daily data as average of the 4 working days before Wednesday and Wednesday itself.

[Insert Figure 3.1.3] and [Insert Figure 3.1.4]

As stressed above, the explanatory variables we use are the same among the two markets (Euribor and Libor), since they are indicators of market phenomenon (such as assets deflation, bank run, liquidity tensions, rising counterparty risk) which are common to both the markets.

As Figures 3.1.2, 3.1.3 and 3.1.4 show, during the beginning of August when the Subprime crisis exploded the Spread, the CPs outstanding volumes and the VIX experienced all a sharp departure from their historical trends. The VIX and the Spread increased suddenly both in the constant value and in the volatility, while the CP had the inverse behaviors. The CDS increases more constantly during the financial crisis period, while it exploded only during March 2008 with the collapse of Bear Stern.

Table 3.1.1 reports the descriptive statistics of the variables we considered along with their logarithmic transformation. As shown, the log transformation reduces the values of the Jarque-Bera test. The probabilities of the tests show that we are far from the acceptance of normality hypothesis; nevertheless, the gain towards normality is substantial for many variables. For this reason the log transformation of the variables are considered in the regression models. The ADF test statistic indicates that each variable has a unit root in either panels thus we must be careful when we estimate our model with the OLS; indeed we have to avoid possible spurious regressions.

\footnotetext{
${ }^{6}$ We use weekly data, because the FED makes public the Commercial Paper release each Wednesday.
} 
[Insert Table 3.1.1] and [Insert Table 3.1.2]

\subsection{Regression Analysis}

We follow the Engle-Granger two-step estimation approach. In the first step, we estimate our model using the level of the variables (even if they are integrated of order one) and then check the residuals. The static model has the form:

$$
y_{t}=c+\sum_{i=1}^{m} \gamma_{i} x_{i t}+u_{t}
$$

where $y_{t}$ interprets the Spread variable, $\left\{x_{i t}, i=1, \ldots, m\right\}$ are the explanatory variables, and $u_{t}$ the error term.

If we reject the presence of unit roots on the residual series $\hat{u}_{t}$, then there is a consistent long-run relationship between the variables, because the variables which enter in the long-run regression are cointegrated. More specifically, in this case the OLS estimators of the long-run coefficients $\left\{\gamma_{i}, i=1, \ldots, m\right\}$ are super-consistent and we use the residuals as a computed regression variable (the ECM component) in the second step where we estimate the short-run regression in ECM form.

Looking at the spread behavior, an important remark regards the possibility to insert a dummy variable at the beginning of August 2007 in coincidence with the explosion of the financial subprime financial crisis. From econometric point of view this rapid upward behaviour and change of volatility could be considered as a structural break that can be modeled in various ways. We can use a step dummy or a switching regime model or something else. Those methods lead to a better fit of the regression equations due to insertion of more parameters that increase the flexibility of the models. In opposition to this advantage, a less good aspect is the difficult interpretation of the estimated parameters of the model. Often the insertion of dummies or more parameters compensates for absence of omitted and (unfortunately) unobservable explanatory variables that become more relevant in the transition, that is, pre and post the breaking period. Moreover, in the same transition period it might partially hide the contribution of the other variables which are actually inserted in the equations and might act as good proxies of the ones unobservable and omitted.

For this reason we exclude the use of dummies in this contest and we leave to the risk variable to explain entirely their contribution to the spread.

The results for the first step are reported in Table 3.2.1a and Table 3.2.1b respectively.

[Insert Table 3.2.1a] and [Insert Table 3.2.1b] 
The ADF tests on the residual series reject the hypothesis of the presence of unit roots: the value of the ADF statistic is -4.436 for Euribor ECM component and -4.810 for Libor ECM component. Both the computed values define a critical region which contains the test statistic variable with a probability very near zero. Consequently, the coefficient estimates can be interpreted as long-run coefficients.

Regarding Euribor-Eonia spread, we can underline that all the expected signs of the explanatory variables are fulfilled and the relative importance of the impacts on the spread is given by the CDS and CP variables.

The link between the Spread and the CDS is positive as expected: if the banking sector is facing an increase of the probability of default, the spread will be higher. The relationship between Spread and CP volume is negative and also economically significant as expected in line with the arguments presented in Section 2. This is another relevant variable and indicates that tension on the CP markets and the dry-up of one segments of this market: the ABCP, has produced a huge demand of liquidity in the interbank market as well as the large losses that has increased the Spread. The results for VIX confirm its ability to capture liquidity and market risk as well as credit risk.

More specifically, a change of $1 \%$ of the CDS value has an increasing impact of $0.6 \%$ in the Euribor-Eonia spread. Regarding the volume of $\mathrm{CP}$, again we observe that an increase of $1 \%$ has a reduction impact of $2.5 \%$ of the Euribor-Eonia spread. A reduction of $1 \%$ of VIX contributes to a smaller spread of $0.4 \%$. These results highlights the importance of liquidity risk variables like the $\mathrm{CP}$ volumes in explaining the long-run dynamics of the spread, an aspect so far ignored by the previous empirical literature.

Concerning the liquidity injection variables, the most important are ECB_REFI_RATE that reduces the spread of an amount a bit over the $7 \%$ if it decreases of 25 basis points and ALLOTTED_LTRO, which affects the spread of $-0.2 \%$ per 1 billion Euros increment. The other intervention variables have minor effects but not irrelevant ${ }^{7}$.

The Figure 3.2.1a reports the long-run curves, i.e. the estimation of the expected values of spreads given the explanatory risk and CBI variables. The figure shows that the fitted long-run curve of the Euribor-Eonia Spread has a jump corresponding to the inception of the sub-prime financial crisis in August 2007.

[Insert Figure 3.2.1a]

Table 3.2.1b shows that the prominent variable that influences the Libor-OIS spread is CDS and CP followed by the intervention variables ALLOTTED_TAF and SAT_RATE_TALF. The wrong sign appears only for SAT_RATE_TSLF, which seems to have an opposite compensating effect with respect to SAT_RATE_TALF.

\footnotetext{
${ }^{7}$ Measuring the changes in standard deviation units rather than natural or percentage terms, $1 \%$ increasing value of CDS has an increasing impact of $0.73 \%$ in the Euribor-Eonia spread and $1 \%$ increasing in the volume of CP entails a reduction impact of $0.59 \%$. Smaller volatility of $1 \%$ reduces the spread of $0.16 \%$. Similarly, ECB_REFI_RATE reduces the spread of $0.33 \%$ if it decreases of $1 \%$ standard unit and ALLOTTED_LTRO affects the spread of $0.44 \%$ per $1 \%$ increment.
} 
The economic impact of a change of $1 \%$ of CDS in this case has an impact of $0.83 \%$ in the Libor-OIS spread that is we observe a relationship near one to one between the Libor-OIS spread and the CDS spread. Regarding the CP, a change of $1 \%$ the effect is a reduction of $1.53 \%$ of the Libor-OIS spread. A reduction of $1 \%$ of VIX contributes to a smaller spread of $0.56 \%$.

With reference to the liquidity injection variables, a relevant role is played by ALLOTTED_TALF: its increase of 1 billion dollars affects the spread of $-2.71 \%$. Also ALLOTTED_TAF and SAT_RATE_TSLF have good long-run impacts on the spread. The values are respectively of $-0.18 \%$ per 1 billion dollars and of $-0.93 \%$ per $1 \%$ increment of satisfaction rate. The other intervention variables have minor effects but not irrelevant ${ }^{8}$.

A particular consideration should be done for the FED_FUNDS_TARGET_RATE. Its long-run impact is not statistically significant. The low relevance of the FED reference rate is consistent with the FED monetary policy, i.e. with its choice to keep the reference rate at the floor.

[Insert Figure 3.2.1b]

Notice that not every intervention variables affect the spread in the long-run. If we use the AIC criterion for the selection of the significant regression coefficients, then ALLOTTED_MRO, BID_MRO, NBIDDERS_LTRO and SAT_RATE_LTRO do not contribute to reduce the difference between Euribor and Eonia (in the reduced static model $m=8$ ).

This result should not surprise, most of the intervention variables have similar description of the $\mathrm{CB}$ reaction to control the liquidity in the financial sector and the regression analysis selects the ones more appropriate among them inside the sample period. Nothing to say, the excluded variables from the long-run regression could affect the spread in the short-run.

The short-run regression assumes the ECM form:

$$
\Delta y_{t}=c+\sum_{i=1}^{p-1} \alpha_{i}^{*} \Delta y_{t-i}+\sum_{j=1}^{m} \sum_{i=0}^{q_{j}-1} \beta_{i j}^{*} \Delta x_{j t-i}+\lambda \hat{u}_{t-1}+\varepsilon_{t}
$$

where $p-1$ and $\left\{q_{j}-1, j=1, \ldots, m\right\}$ are the minimum lag orders to assure that $\varepsilon_{t}$ can be supposed a white noise error term and $\hat{u}_{t}$ represents the ECM component. The

\footnotetext{
${ }^{8}$ Measuring the changes in standard deviation units rather than natural or percentage terms, $1 \%$ increasing value of CDS has an increasing impact of $1 \%$ in the Libor-OIS spread, that is, we observe a one to one relationship between the Libor-OIS spread and the CDS spread. Regarding the CP, a change of $1 \%$ the effect is a reduction of $0.36 \%$ of the Libor-OIS spread. Smaller volatility of $1 \%$ reduces the spread of $0.23 \%$.

With reference to the liquidity injection variables, ALLOTTED_TALF increment of $1 \%$ affects the spread of $-0.75 \%$. Also ALLOTTED_TAF and SAT_RATE_TSLF have good long-run impacts on the spread respectively of $-0.34 \%$ and $-0.30 \%$.
} 
stability condition of the ECM model is satisfied if the parameter $\lambda$ is inside the negative open interval $(-2,0)$.

In the short-run regression we use again the AIC criterion, firstly for deciding the minimum lag orders mentioned above, subsequently for the regressors selection. For Euribor, AIC criterion agrees with the other information criteria of Schwarz and Hannan-Quinn: the choice is in favor of lag 1. A diverse result we obtain for Libor Spread: the Akaike criterion, differently from the other criteria, has two relative minimum values at -1.292 (lag 4) and -1.307 (lag 1). A prudential choice suggests considering the general dynamic model with four lags for the Libor Spread ${ }^{9}$.

The results of the specifications of the regressions, using the 'general to specific' modelling method, are shown in Table 3.2.2a and Table 3.2.2b.

[Insert Table 3.2.2a]

[Insert Table 3.2.2b]

As the tables show, the dynamic is driven mainly by the lagged dependent variable and by ECM component. The autoregressive component explains the positive inertia of spread movements and the discrepancies between the expected and actual spread play the most relevant role for the short-run curve. Furthermore, the intercept is highly not significant: the evidence of zero intercept in presence of unit roots in levels leads to the exclusion of deterministic trends in the spread series.

The R-squared of the regression is low at 0.27 for Euribor Spread and 0.44 for Libor Spread. This is due to the high value of total variance explained by the long-run curve (91.3\% and $90.9 \%$ respectively) and it is also the consequence of stationarity of the differenced dependent variable. Anyway, it should be underlined that the short-run curve adds an incremental contribution of $7.8 \mathrm{R}$-squared units in explaining the total variance of the spread, therefore the long-run curve and the short-run curve together reach the $99.1 \%$. Similarly the incremental contribution of the short-run curve in the case of Libor Spread is of 8.2 R-squared units.

The residuals are not autocorrelated and not even heteroskedastic for the Euribor Spread. Some problems arise with the deviation from the normality. The empirical distribution appears positively skewed and with a large excess of kurtosis. The explanation of this deviation is almost entirely given by the jump of residuals at the beginning of the financial crisis that happened unexpectedly at the second week of August 2007 (8/08/2007 in our sample). In fact, if we insert an impulse dummy at this date, then we have a substantial reduction of the skewness (from 1.96 to -0.21) and kurtosis (from 21.60 to 5.33). On the contrary, the Libor Spread residuals are

\footnotetext{
${ }^{9}$ Results are provided upon request.
} 
characterized by the presence of light heterosckedasticity which cannot be reduced using dummies ${ }^{10}$.

\subsection{The impulse response functions}

It is well known that the model (3) and (4) can be written in ADL form:

$$
y_{t}=c+\sum_{i=1}^{p} \alpha_{i} y_{t-i}+\sum_{j=1}^{m} \sum_{i=0}^{q_{j}} \beta_{i j} x_{j t-i}+\varepsilon_{t}
$$

or:

$$
\alpha(L) y_{t}=c+\sum_{j=0}^{m} \beta_{j}(L) x_{j t}+\varepsilon_{t}
$$

where $L$ is the lag operator, $\alpha(L)=1-\alpha_{1} L-\cdots-\alpha_{p} L^{p}$ and $\beta_{j}(L)=\beta_{0}+\beta_{1 j} L+\cdots+\beta_{q_{j}, j} L^{q_{j}}, j=1, \ldots, m$.

The parameters $\alpha$ and $\beta$ can be easily computed from the parameters of the static equation (3) and ECM form (4) by using the following relations:

(7) $\left\{\begin{array}{l}\alpha_{0}=1 \\ \alpha_{1}=1-\alpha(1)+\alpha_{1}^{*} \\ \alpha_{i}=\alpha_{i}^{*}-\alpha_{i-1}^{*}, \quad i=2, \ldots, p-1 \\ \alpha_{p}=-\alpha_{p-1}^{*}\end{array}\right.$

$$
\left\{\begin{array}{l}
\beta_{0 j}=\beta_{0 j}^{*} \\
\beta_{1}=\alpha(1) \gamma_{j}+\beta_{1 j}^{*}-\beta_{0 j}^{*} \\
\beta_{i j}=\beta_{i j}^{*}-\beta_{i-1 j}^{*}, \quad i=2, \ldots, q-1 \\
\beta_{q}=-\beta_{q-1}^{*} \\
j=1, \ldots, m
\end{array}\right.
$$

where $\alpha(1)=1-\alpha_{1}-\cdots-\alpha_{p}$.

The corresponding final form of (6) is:

$$
\begin{aligned}
y_{t} & =c \alpha(1)^{-1}+\sum_{j=1}^{m} \beta_{j}(L) \alpha(L)^{-1} x_{j t}+\alpha(L)^{-1} \varepsilon_{t} \\
& =c *+\sum_{j=0}^{m} h_{j}(L) x_{j t}+\varepsilon_{t}^{*}
\end{aligned}
$$

where $h_{j}(L)=\beta_{j}(L) \alpha(L)^{-1}, c^{*}=c \alpha(1)^{-1}, \varepsilon_{t}^{*}=\alpha(L)^{-1} \varepsilon_{t}$.

\footnotetext{
${ }^{10}$ The distribution of the residuals is provided upon request.
} 
Stability conditions of the model imply that all the roots of the polynomial equation $\alpha(L)=0$ lie outside the unit circle so that the inverse polynomial $\alpha(L)^{-1}$ exists. If the stability conditions are satisfied then $h_{j}(L)=\sum_{k=0}^{\infty} h_{k, j} L^{k}$ are convergent series and the infinite sequences of the coefficients $\left\{h_{k, j}, j=1, \ldots, m\right\}$ represent the impulse response functions that measure the dynamic response of $y_{t}$ to the unit impulses of the explanatory variables $x_{j t}$.

The sequences $\left\{h_{k, j}, j=1, \ldots, m\right\}$ are computed on the basis of the recursive formula:

$$
\left\{\begin{array}{l}
h_{0, j}=\beta_{0 j} \\
h_{k, j}=\beta_{k, j}+\sum_{i=1}^{r} \alpha_{i} h_{k-i, j} ; \quad k=1, \ldots, q_{j} ; r=\min (k, p) . \\
h_{k, j}=\sum_{i=1}^{r} \alpha_{i} h_{k-i, j} ; \quad k>q_{j}
\end{array}\right.
$$

In our analysis the stability conditions are implicitly satisfied by the cointegration property and ECM representation, therefore we can calculate the empirical response function for each explanatory variable.

In the Appendix A the impulse response functions of Euribor-Eonia Spread are reported. The curves are computed using the formula (9).

Considering that the coefficients $h_{k, j}$ are functions of the parameters $\alpha$ and $\beta$, that is, $h_{k, j}=f_{k, j}\left(\alpha_{i}, \beta_{l j}\right), i=1, \ldots, p ; l=0,1, \ldots, q_{j}$, we used the algorithm based on the partial derivatives of the functions $f_{k, j}$ and the estimated covariance matrix of the model parameters to compute the exact confidence intervals at the $95 \%$ level.

A general remark on these functions is that the unit shocks of almost all the explanatory variables reach their maximum effect in three periods (weeks). Exception is done for the $\mathrm{CP}$, whose negative impact is quicker (53.8\% in two weeks) and for VIX, whose positive shock affects smoothly the spread on the periods: $63.3 \%$ of its impact happens in two weeks, almost $90 \%$ in two months. We can notice the poor dynamic relevance of NBIDDERS_MRO variable, flattened by the wide confidence intervals.

All the intervention variables have an impact on the spread, in term of total increment or decrement $(\Delta)$, which follows this rule: $\Delta / 4$ after the first fortnight, $\Delta / 2$ after 1 month and $3 \Delta / 4$ after 2 months. Slightly faster is the reaction to the BID_LTRO and NBIDDERS_MRO variables. 
The ALLOTTED_MRO and BID_MRO variables do not give any contribution in the long-run, but they contribute in the short-run dynamic of the spread.

The impulse response functions on Libor-OIS spread are plotted in Appendix B.

The behavior of these functions is almost similar to those of the Euribor-Eonia spread even though they are characterized by greater fluctuations along the lags, often alternating positive and negative signs.

Within the credit risk indicators, CP presents an opposite behaviour compared to the impulse response function of Euribor-Eonia spread, but we have to consider that the positive pick after one week is widely compensated by the negative simultaneous impact and by the responses that remain on the negative territory for all the lags after the third week. Furthermore, we observe the same relative persistence of the impact of the VIX variable.

FED_FUNDS RATE has an immediate negative impact half-recovered after one month and completely after two. ALLOTTED_TAF and SAT_RATE_TAF have similar dynamics: two months are sufficient to drain almost completely all the negative impact on the spread. ALLOTTED_TSLF is faster for two weeks. Consistently with the unexpected positive long-run coefficient, SAT_RATE_TSLF affects the spread with a positive wave analogous dynamically to the CDS impact. ALLOTTED_TALF and SAT_RATE_TALF perform a very slow and persistent impact on the spread: their effect is not completed after three months. Finally, the SAT_RATE_PDCF and SAT_RATE_AMLF variables do not give any contribution in the long-run, but they contribute in the short-run dynamic of the spread.

\section{Conclusions}

This paper analyzes the relationship between the collateralized short term debt market of the commercial papers and the unsecured interbank market during the 2007-2008 subprime crisis.

We find that during the crisis period the spread dynamic follows a pattern largely dependent on the outstanding volume of the ABCP. In particular, the paper shows that the $\mathrm{ABCP}$ and the Financial $\mathrm{CP}$ outstanding volumes have an inverse relationship with the spread.

The most significant variable that explains the spread is the CDS index both for Euribor and the Libor markets, followed by CP and VIX. The last one seems to contribute more to the short-run dynamics than the long-run curve.

These finding support the idea that the liquidity tension is the main cause of the huge jump in the Spread during the crisis period. The runs on the short-term securities market create an aggregate systemic liquidity need in the financial sector that obviously cannot be supplied by the only remaining available market: the unsecured interbank market. Under normal times this liquidity injections is offered by the Central Banks, but especially during the second part of the crisis the Central Banks were not able to provide the liquidity requested by the market, because also Central Banks for providing liquidity require a collateral.

This is confirmed by the fact that the Spread is not affected at all neither by traditional Central Banks interventions (Open Market Operations where the Central Banks give 
liquidity against high quality collateral) nor by cuts in key policy rates. However, "nonconventional" measures do have an impact, as our analysis shows.

In particular, for the ECB the most relevant intervention in the long-run is the REFI rate and the Long-Term Refinancing Operation (LTRO allotted). For the FED in the longrun relevant interventions are the Term Auction Facility (TAF, allotted) and the Term Asset-Backed Securities Loan Facility (TALF, allotted). The FED Fund Target Rate is not relevant in the long-run but it contributes to the short-run dynamic.

The main lessons that we can learn from this analysis is that the Euribor and the Libor rates cannot be used any more as benchmark for other markets rates. Indeed, first, the Central Banks cannot efficiently control these rates with their ordinary tools but only with the addition of "non conventional" measures. This is particularly true when the Central Bank needs to control them more, i.e. during crisis. Credit risk and liquidity tensions in the short-term securities market make the Euribor and Libor rates dynamic largely unrelated to the Central Banks target rates. Therefore, the Central Banks have to constantly monitor the dynamic of these two variables: CDS and CP volume.

Furthermore, if the monetary policy has to be fully transferred into real economy rates, changes in key central rates must be fully transferred to the benchmark rates and thus the later must be always attached to the former and if they don't the Central Banks must be able to steer them back. Moreover, a new benchmark must be found and it must be a market rate of short term loans collateralised by safe assets (as the GC Eurepo for example). Only in this case the Central Banks could, with their ordinary tools, control it. However further research on the topic must be done. 


\section{References}

Adrian T. and Shin H. S. (2010), "Liquidity and leverage", Journal of Financial Intermediation, 19 (3), 418-437

Adrian T. and Shin H. S. (2011), "Financial Intermediary Balance Sheet Management", Annual Review of Financial Economics, 3, 289-307.

Bank of England, “An Indicative Decomposition of Libor Spreads”, Quarterly Bulletin, December 2007 pp. 498-9.

Bernanke B. S. (1983), "Non-Monetary Effects of the Financial Crisis in the Propagation of the Great Depression", NBER Working Paper $n^{\circ} 1054$, January 1983.

Bernanke B. S. and Gertler M. (1995), "Inside the Black Box: The Credit Channel of Monetary Policy Transmission", The Journal of Economic Perspectives, Autumn 1995.

Bernanke B. S. and Gertler M. (1996), "The Financial Accelerator and the Flight to Quality", The Review of Economics and Statistics, February 1996.

Brunnermeier M. (2009) "Deciphering the 2007/08 Liquidity and Credit Crunch", Journal of Economic Perspectives, 23, 1, 77-100.

Brunnermeier, M. and Pedersen, L. H. (2008), "Market liquidity and funding liquidity", Review of Financial Studies, 22, 6, 2201-2238.

Casarin R., Sartore D. and Zabotto F. (2012), "Measuring the ECB and the FED Liquidity Injection Variables", mimeo.

Diamond D.W. and Dybvig P. H. (1983,2000), "Bank Runs, Deposit Insurance and Liquidity", Journal of Political Economy, June 1983 (reviewed Winter 2000).

European Central Bank (2007), Euro Money Market Study 2006, ECB publication.

Gorton G. B. (2008), “The Subprime Panic”,NBER Working Paper $n^{\circ} 14398$, October 2008.

Holmstrom B. And Tirole J. (1997), "Financial Intermediation, Loanable Funds, and the Real Sector", The Quarterly Journal of Economics, August 1997.

McAndrews J., Asani S. and Wang Z. (2008), "The Effects of the Term Auction Facility on the London Inter-bank Offered Rate", Federal Reserve Bank of New York, May 19.

Michaud F. and Upper C. (2008), "What Drives Interest Rates? Evidence from the Libor Panel”, BIS Quarterly Review, March 2008, pp. 47-58.

Taylor J. B. and Williams J. C. (2009), “A Black Swan in the Money Market” American Economic Journal: Macroeconomics, 1,1, 58-83.

Wu T. (2008), "On the Effectiveness of the Federal Reserves New Liquidity Facilities", Working Paper Federal Reserve Bank of Dallas, 2008. 


\section{Figures to be included in the body text}

Figure 3.1.1. - Euribor-OIS and Libor-OIS Spreads

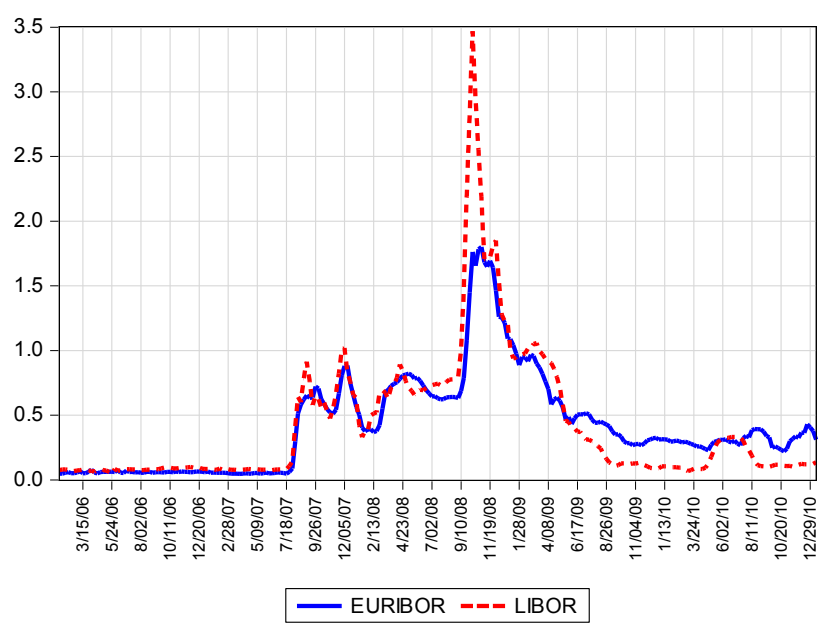

Figure 3.1.2. - Commercial Papers (CP) outstanding volumes
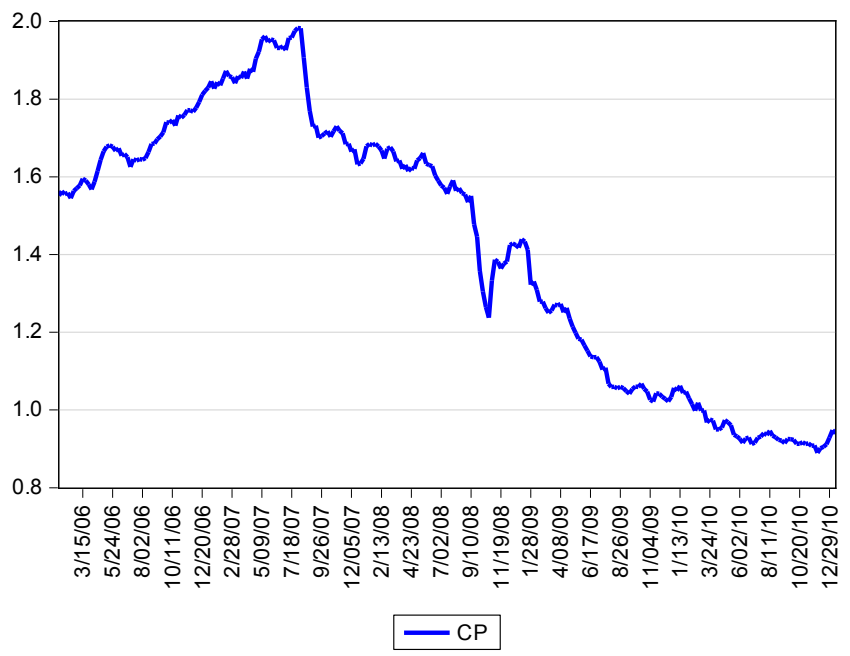

Figure 3.1.3. - Chicago Board Options Exchange Volatility Index (VIX)

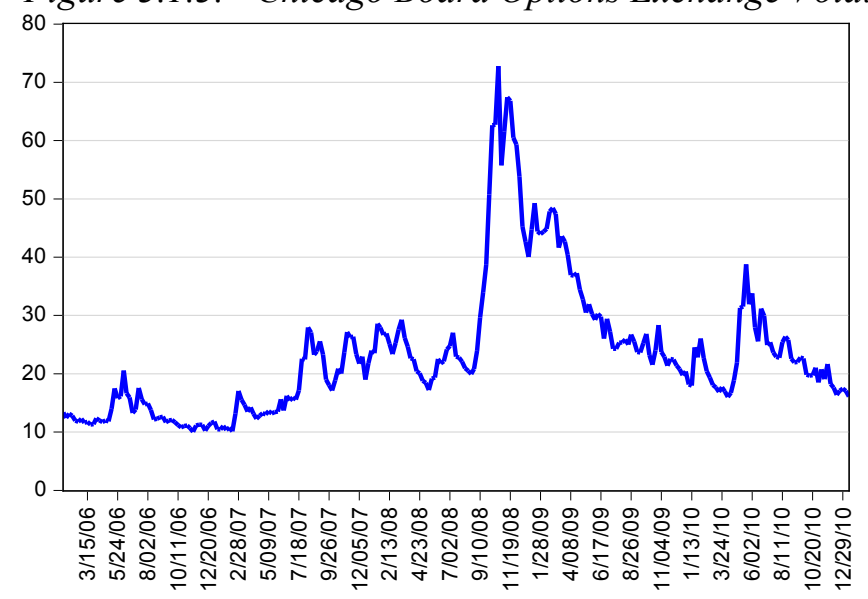


Figure 3.1.4. - Credit Default Swap Index for the US financial sector (CDS)

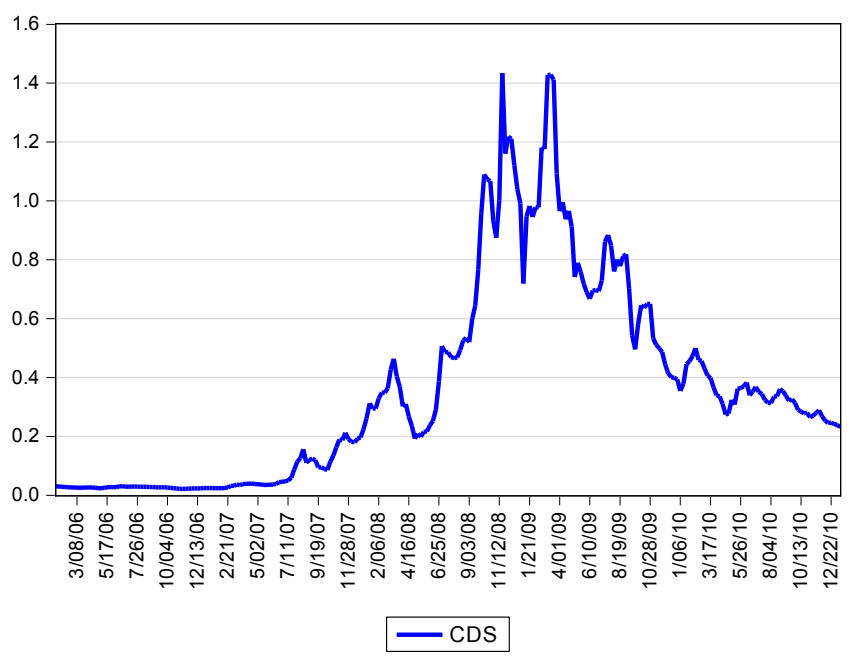

Fig. 3.2.1a - Long-run Curve of the Euribor-Eonia Spread

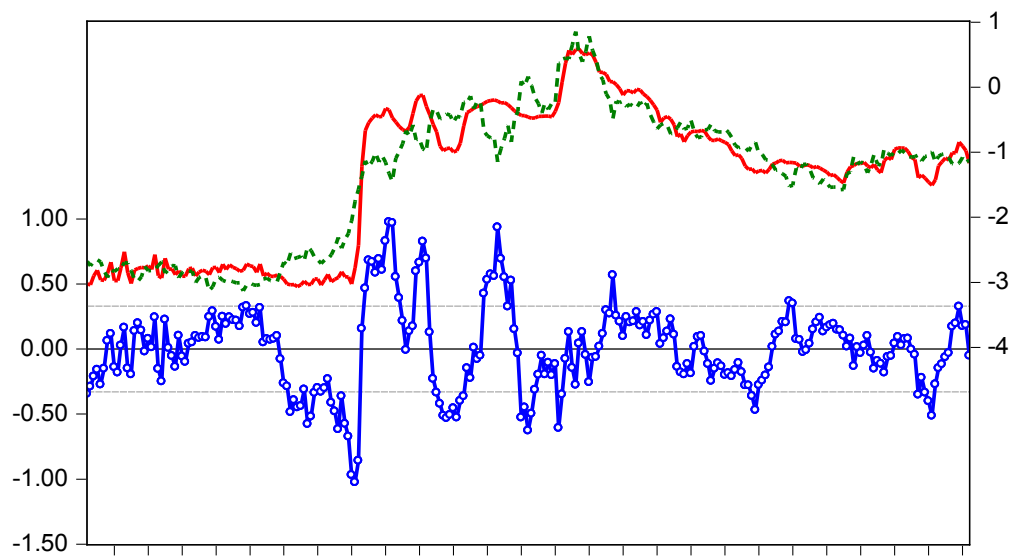

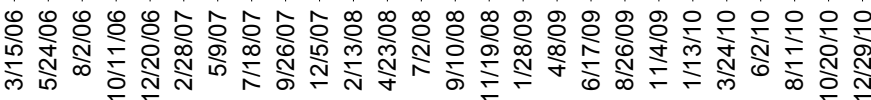

$\multimap$ ECM - Actual ---- Long-run 
Fig. 3.2.1b - Long-run Curve of the Libor-OIS Spread

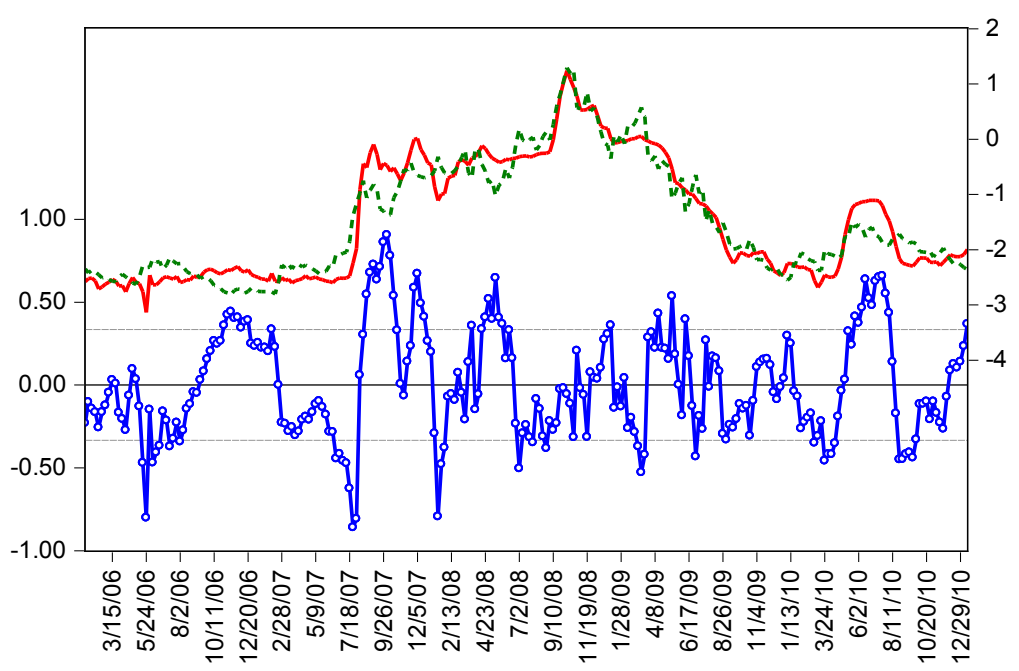

$\longrightarrow$ ECM $\longrightarrow$ Actual ----- Long-run 
Table 3.1.1. Descriptive statistics of the spreads

\begin{tabular}{lrrrr}
\hline & $\begin{array}{c}\text { SPREAD } \\
\text { EURIBOR }\end{array}$ & $\begin{array}{c}\text { LOG SPREAD } \\
\text { EURIBOR }\end{array}$ & $\begin{array}{c}\text { SPREAD } \\
\text { LIBOR }\end{array}$ & $\begin{array}{c}\text { LOG SPREAD } \\
\text { LIBOR }\end{array}$ \\
\hline Mean & & & & \\
Median & 0.421099 & -1.358383 & 0.424801 & -1.466580 \\
Maximum & 0.322200 & -1.132583 & 0.128488 & -2.051920 \\
Minimum & 1.801200 & 0.588453 & 3.469750 & 1.244083 \\
Std. Dev. & 0.046600 & -3.066155 & 0.043804 & -3.128030 \\
Skewness & 0.380965 & 1.100925 & 0.524378 & 1.085932 \\
Kurtosis & 1.448564 & -0.325190 & 2.523459 & 0.489929 \\
& 5.364027 & 1.757965 & 11.44157 & 1.816808 \\
\hline Jarque-Bera & & & & \\
Probability & 152.0540 & 21.37641 & 1051.954 & 25.66569 \\
\hline & 0.000000 & 0.000023 & 0.000000 & 0.000003 \\
\hline
\end{tabular}

Table 3.1.2. Descriptive statistics of the credit risk variables

\begin{tabular}{lcrrrrr}
\hline & CDS & LOG(CDS) & CP & LOG(CP) & VIX & LOG(VIX) \\
\hline Mean & 0.361852 & -1.686005 & 1.424997 & 0.322627 & 23.44088 & 3.052756 \\
Median & 0.290456 & -1.236302 & 1.558638 & 0.443813 & 21.72200 & 3.078326 \\
Maximum & 1.434171 & 0.360587 & 1.983218 & 0.684721 & 72.78200 & 4.287469 \\
Minimum & 0.021542 & -3.837733 & 0.890061 & -0.116465 & 10.04400 & 2.306975 \\
Std. Dev. & 0.345343 & 1.344307 & 0.344314 & 0.256852 & 11.73749 & 0.437920 \\
Skewness & 1.075298 & -0.396077 & -0.200764 & -0.390345 & 1.713184 & 0.464704 \\
Kurtosis & 3.448818 & 1.687203 & 1.582693 & 1.622303 & 6.302188 & 2.925272 \\
& & & & & & \\
\hline Jarque-Bera & 52.48815 & 25.56650 & 23.59856 & 27.26935 & 246.2584 & 9.454533 \\
Probability & 0.000000 & 0.000003 & 0.000008 & 0.000001 & 0.000000 & 0.008851 \\
\hline
\end{tabular}

Table 3.2.1a - Long-Run Regression of the Euribor-Eonia Spread (Dependent Variable: LOG(SPREAD_EURIBOR))

\begin{tabular}{lccc}
\hline Variable & $\begin{array}{c}\text { Expected } \\
\text { Sign }\end{array}$ & Coefficient & Std. Error $\left(^{\circ}\right)$ \\
\hline COSTANT & & -0.590 & 0.715 \\
LOG(CDS) & + & $0.601^{* * *}$ & 0.074 \\
LOG(CP) & - & $-2.529^{* * *}$ & 0.490 \\
LOG(VIX) & + & $0.402^{* *}$ & 0.176 \\
ECB_REFI_RATE & + & $0.281^{* * *}$ & 0.071 \\
ALLOTTED_LTRO & - & $-1.962^{* * *}$ & 0.629 \\
BID_LTRO & + & $1.232^{*}$ & 0.635 \\
NBIDDERS_MRO & + & $1.045^{* * *}$ & 0.365 \\
SAT_RATE_MRO & - & $-0.012^{*}$ & 0.006 \\
\hline
\end{tabular}

$R^{2}=0.913, \hat{\sigma}=0.330$, AIC $=0.653$

${ }^{\circ}{ }^{\circ}$ Newey-West Heteroskedasticity AutoCorrelation (HAC) consistent standard errors *** denotes significance at the 1\% level, ** at the 5\% level, and * at $10 \%$ level 
Table 3.2.1b - Long-Run Regression of the Libor-OIS Spread (Dependent Variable: LOG(SPREAD_LIBOR))

\begin{tabular}{lccc}
\hline Variable & $\begin{array}{c}\text { Expected } \\
\text { Sign }\end{array}$ & Coefficient & Std. Error $\left(^{\circ}\right)$ \\
\hline COSTANT & & -0.888 & 1.053 \\
LOG(CDS) & + & $0.830^{* * *}$ & 0.154 \\
LOG(CP) & - & $-1.530^{* *}$ & 0.750 \\
LOG(VIX) & + & $0.560^{* *}$ & 0.270 \\
FED_FUNDS_TARGET_RATE & + & 0.157 & 0.129 \\
ALLOTTED_TAF & - & $-1.841^{* * *}$ & 0.521 \\
ALLOTTED_TALF & - & $-27.435^{* * *}$ & 6.522 \\
ALLOTTED_TSLF & - & $-0.321^{*}$ & 0.168 \\
SAT_RATE_TAF & - & $-0.004^{*}$ & 0.002 \\
SAT_RATE_TALF & - & $-0.005^{* * *}$ & 0.002 \\
SAT_RATE_TSLF & - & $0.009^{* * *}$ & 0.002 \\
\hline
\end{tabular}

$R^{2}=0.909, \hat{\sigma}=0.334, A I C=0.686$

${ }^{\circ}{ }^{\circ}$ Newey-West Heteroskedasticity AutoCorrelation (HAC) consistent standard errors *** denotes significance at the $1 \%$ level, $* *$ at the $5 \%$ level, and $*$ at $10 \%$ level

Table 3.2.2a - Short-Run Regression of the Euribor-Eonia Spread (Dependent Variable: $\triangle L O G\left(S P R E A D \_E U R I B O R\right)$

\begin{tabular}{lcc}
\hline Variable & Coefficient & Std. Error $\left({ }^{\circ}\right)$ \\
\hline COSTANT & 0.003 & 0.007 \\
$\Delta$ LOG(SPREAD_EURIBOR(-1)) & $0.376^{* * *}$ & 0.131 \\
$\Delta$ LOG(CP(-1)) & $-0.693^{*}$ & 0.356 \\
ALOG(VIX) & $0.227^{* *}$ & 0.104 \\
AALLOTTED_MRO & $1.256^{* *}$ & 0.605 \\
$\Delta$ ALLOTTED_MRO(-1) & $-0.338^{*}$ & 0.197 \\
$\Delta$ BID_MRO & $-0.902^{* *}$ & 0.449 \\
$\Delta$ SAT_RATE_MRO & $-0.005^{* *}$ & 0.002 \\
ECM_EURIBOR $(-1)$ & $-0.125^{* * *}$ & 0.042 \\
\hline
\end{tabular}

$R^{2}=0.268, \hat{\sigma}=0.112, A I C=-1.507$

( $\left.{ }^{\circ}\right)$ Newey-West Heteroskedasticity AutoCorrelation (HAC) consistent standard errors *** denotes significance at the 1\% level, ** at the 5\% level, and * at $10 \%$ level 
Table 3.2.2b - Short-Run Regression of the Libor-OIS Spread (Dependent Variable: $\triangle L O G\left(S P R E A D \_L I B O R\right)$

\begin{tabular}{|c|c|c|}
\hline Variable & Coefficient & Std. Error $\left(^{\circ}\right)$ \\
\hline COSTANT & 0.0043 & 0.00791 \\
\hline$\Delta$ LOG(SPREAD_LIBOR(-1)) & $0.2782 * *$ & 0.13308 \\
\hline$\Delta$ LOG(SPREAD_LIBOR $(-3))$ & $0.1824 * * *$ & 0.06496 \\
\hline$\Delta \mathrm{LOG}(\mathrm{CP})$ & $-0.9247 * *$ & 0.55415 \\
\hline$\Delta \mathrm{LOG}(\mathrm{CP}(-2))$ & $1.2000 * *$ & 0.55026 \\
\hline$\Delta \mathrm{LOG}(\mathrm{VIX})$ & $0.2856^{* *}$ & 0.11532 \\
\hline$\Delta \operatorname{LOG}(\operatorname{VIX}(-2))$ & 0.1476 & 0.11487 \\
\hline$\Delta \operatorname{LOG}(\operatorname{VIX}(-3))$ & $0.1756 * * *$ & 0.06562 \\
\hline$\Delta$ FED_FUNDS_TARGET_RATE $(-1)$ & $-0.1355^{*}$ & 0.07194 \\
\hline$\Delta$ FED_FUNDS_TARGET_RATE $(-2)$ & $-0.1733 * * *$ & 0.06551 \\
\hline$\triangle$ ALLOTTED_TAF $(-2)$ & $-0.4607 * * *$ & 0.16520 \\
\hline$\triangle$ ALLOTTED_TAF(-3)) & $-0.4756 * * *$ & 0.15563 \\
\hline$\triangle$ ALLOTTED_TALF) & $-16.9263 * *$ & 7.37563 \\
\hline$\triangle$ ALLOTTED_TALF $(-3))^{-}$ & $-9.0642 *$ & 5.14589 \\
\hline$\triangle$ ALLOTTED_TSLF(-3)) & $-0.3918 *$ & 0.20533 \\
\hline$\triangle$ SAT_RATE_PDCF) & $-0.0015 * * *$ & 0.00035 \\
\hline$\triangle \mathrm{SAT}$-RATE_PDCF $(-1))$ & $0.0009 * *$ & 0.00038 \\
\hline$\left.\triangle \mathrm{SAT}^{-} \mathrm{RATE}-\mathrm{PDCF}(-3)\right)$ & $0.0013 * * *$ & 0.00033 \\
\hline$\triangle$ SAT_RATE_TAF) & -0.0007 & 0.00042 \\
\hline$\Delta$ SAT_RATE_TAF $(-1))$ & $-0.0022 * * *$ & 0.00072 \\
\hline$\Delta$ SAT_RATE_TAF(-3)) & $-0.0018 * * *$ & 0.00067 \\
\hline$\left.\triangle \mathrm{SAT}^{-} \mathrm{RATE}{ }^{-} \mathrm{TALF}(-2)\right)$ & $0.0008 * * *$ & 0.00029 \\
\hline$\triangle$ SAT_RATE_TSLF $(-2))$ & $0.0011 * *$ & 0.00052 \\
\hline$\triangle$ SAT_RATE_AMLF) & $0.0013 * *$ & 0.00051 \\
\hline$\left.\triangle \mathrm{SAT}^{-} \mathrm{RATE}{ }^{-} \mathrm{AMLF}(-2)\right)$ & $-0.0009 * *$ & 0.00046 \\
\hline$\triangle$ SAT_RATE_AMLF(-3)) & $-0.0026^{* * *}$ & 0.00060 \\
\hline $\mathrm{ECM}^{-} \operatorname{LIBOR}(-1)$ & $-0.1256 * * *$ & 0.03247 \\
\hline
\end{tabular}

$R^{2}=0.435, \hat{\sigma}=0.112$, AIC $=-1.422$

${ }^{\circ}{ }^{\circ}$ Newey-West Heteroskedasticity AutoCorrelation (HAC) consistent standard errors

*** denotes significance at the $1 \%$ level, $* *$ at the $5 \%$ level, and $*$ at $10 \%$ level 


\section{Appendix A - Impulse Response Functions on the Euribor-Eonia Spread}
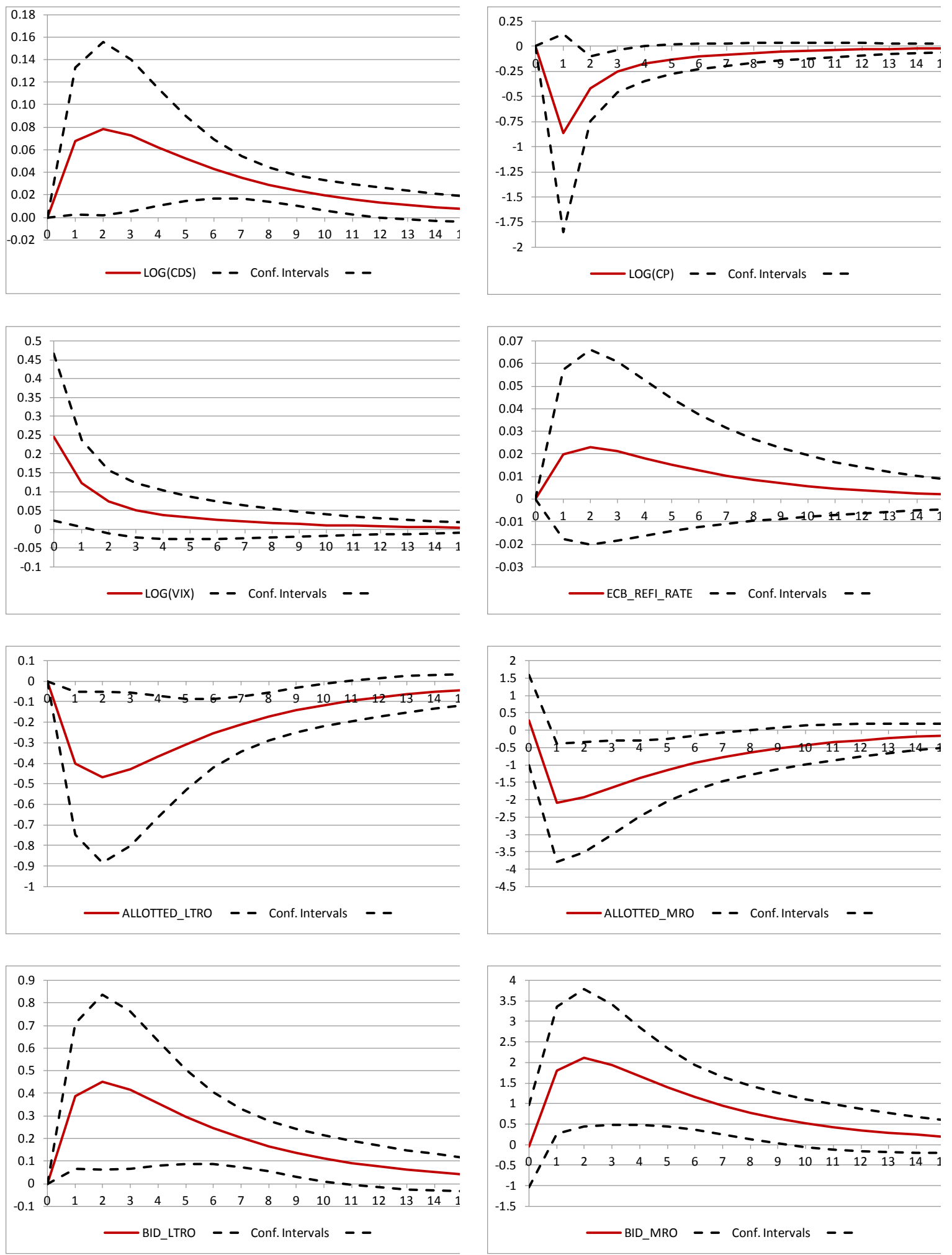

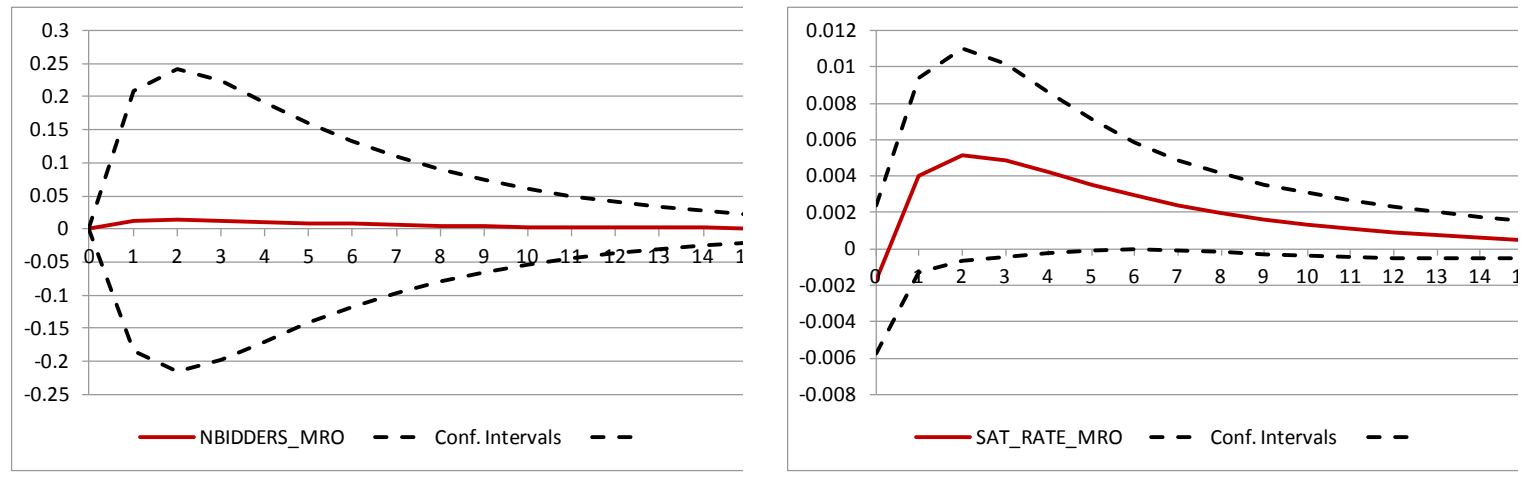


\section{Appendix B - Impulse Response Functions on the Libor-OIS Spread}
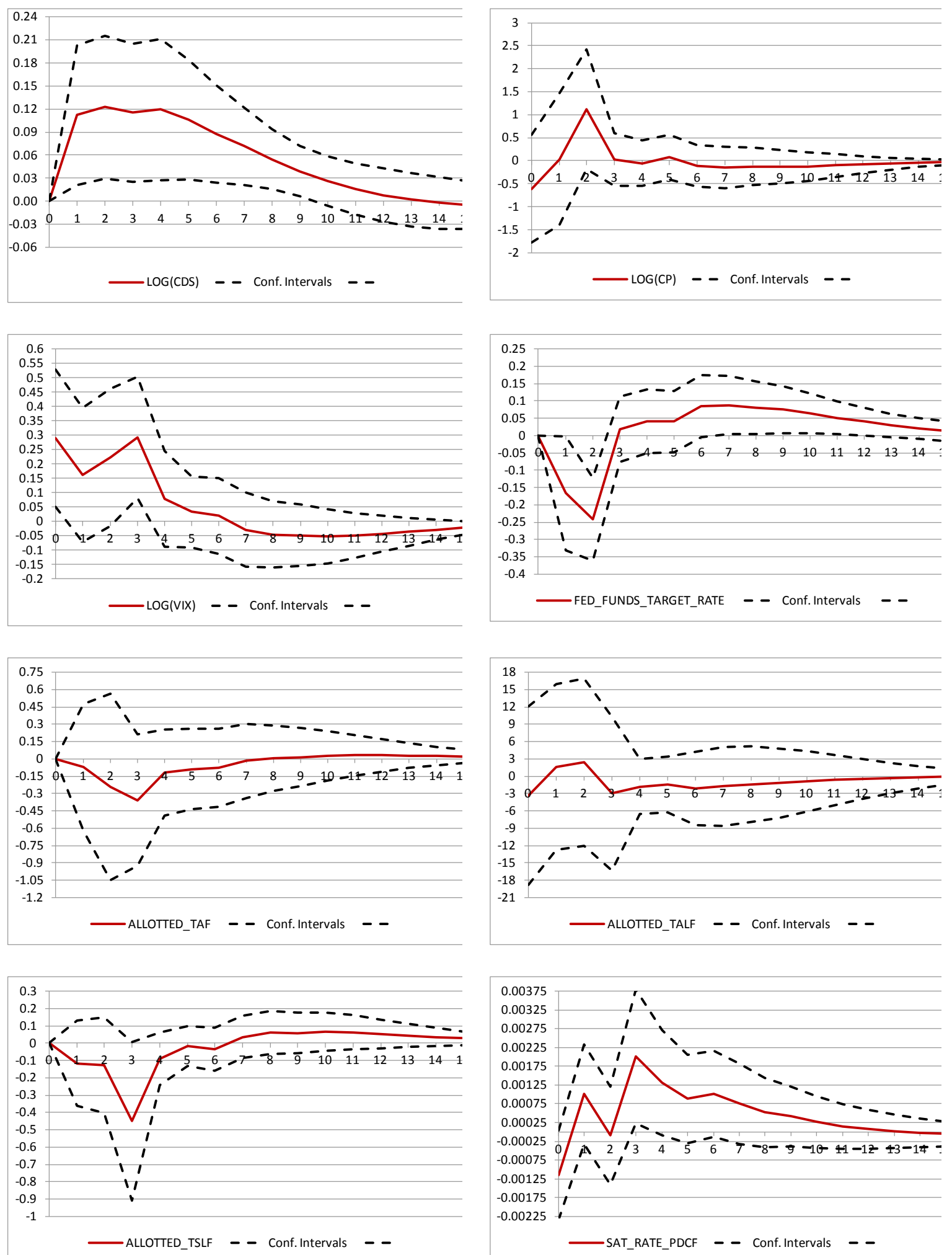

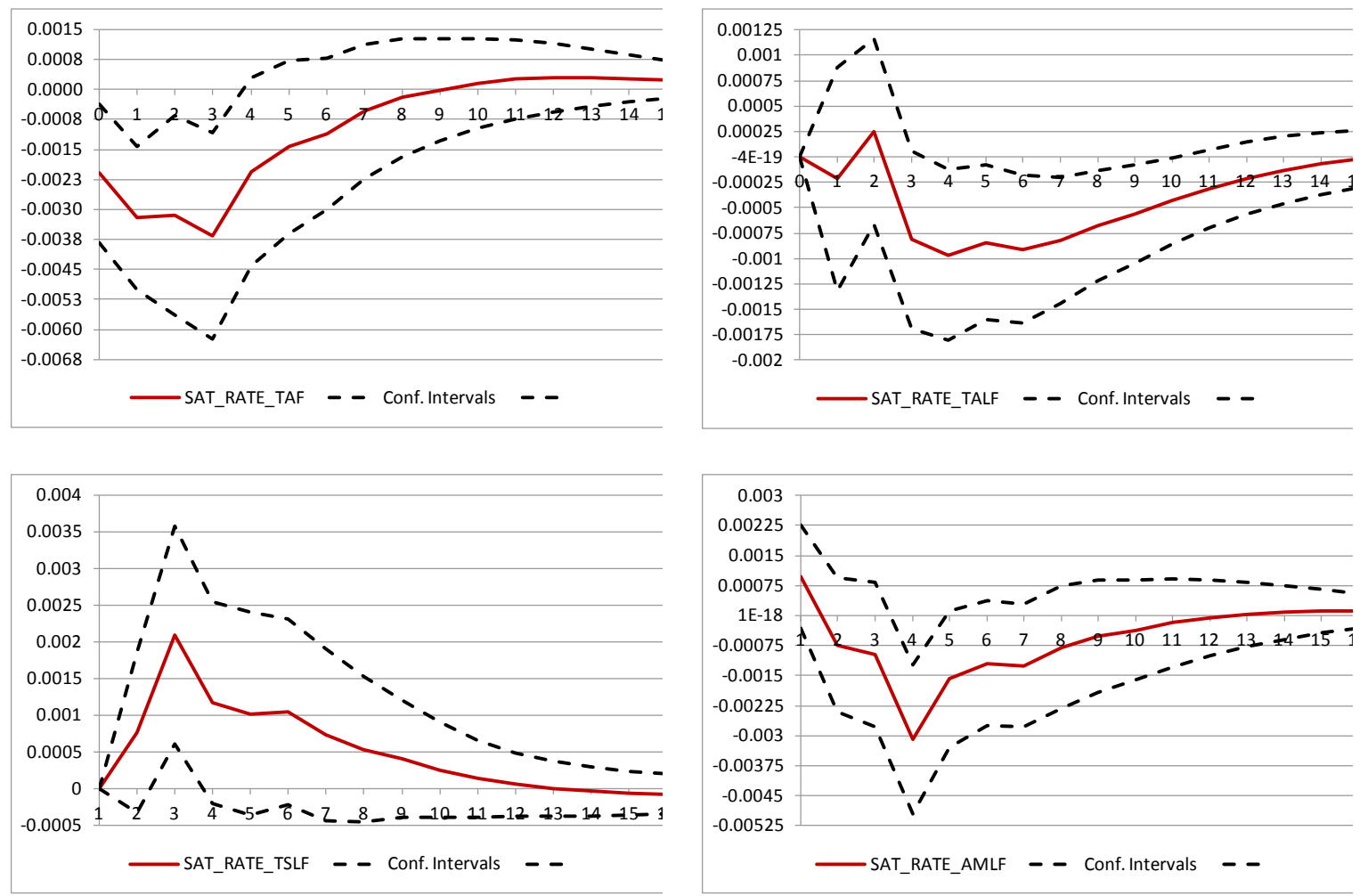